\title{
ASTROVIRUS INFECTION IN CHILDREN IN LAGOS, NIGERIA
}

\author{
Ayolabi, C.I. ${ }^{*}$, Ojo, D.A. ${ }^{2}$, Akpan, I. ${ }^{2}$ \\ ${ }^{1}$ Dept .of Microbiology, University of Lagos, Nigeria; ${ }^{2}$ Dept. of Microbiology \\ University of Agriculture, Abeokuta, Nigeria \\ * Email: ciayolabi@yahoo.co.uk
}

\begin{abstract}
A preliminary investigation was conducted to screen for astrovirus in Lagos. Two hundred and fifteen (215) faecal samples collected from children under 5 years old with diarrhoea (161) and without diarrhoea (54) admitted at paediatric clinics in Lagos State were studied. The stool specimens were examined for the presence of human astrovirus antigen using a monoclonal antibody-based ELISA (Astrovirus RIDASCREEN ${ }^{\circledR}$ r-Biopharm, Germany) technique. Astrovirus was detected in 40.4 percent $(65 / 161)$ of the diarrhoeal stools compared to 11.1 percent $(6 / 54)$ of the control specimens. Astrovirus was found to infect younger children and about three quarter of the children infected was under 12 months of age. The prevalence of infection decreases with age group and was statistically significant $(\mathrm{P}=0.0470)$. Although, prevalence of infection is more in males than females but this is not significant. This study shows that astrovirus is an important agent of acute gastroenteritis among children in Lagos state.
\end{abstract}

Keywords: Astrovirus, diarrhoea, Children, Lagos

\section{Introduction}

Astroviruses are small, non-enveloped positive sense, single stranded RNA viruses in the family astroviridae. They cause gastroenteritis and are found in the stools of several vertebrates including humans. Transmission of the virus from infected to uninfected animal/human is via the fecal-oral route. There are at least eight human serotypes and the prototype species is human astrovirus-1(HAstV-1) (Kakizawa et al., 1997). The aetiology of most diarrhoeal episodes was unknown before 1972 and illnesses were attributed to diet and weaning foods, malnutrition or unexplained causes referred to as 'idiopathic'. Much of the diagnostic gap has been filled in by the discovery of more than a dozen different pathogens and it is now believed that most of these episodes have an infectious aetiology and are caused by micro organisms (Flewett et al., 1974). Agents identified as cause of severe diarrhoeal diseases include bacteria, parasites and viruses (O'Ryan, 2005; Mims et al., 1999 and Tiemessen et al., 1989) Viruses account for $75 \%$ of infantile gastroenteritis and are known to be potent inducers of diarrhoea, vomiting and subsequent dehydration (Christensen, 1989). Several viruses cause diarrhoea and are responsible for most hospitalisations and mortality in young children (Goodgame, 2001). The major viruses known to cause gastroenteritis in humans are Astroviruses, Adenoviruses, Caliciviruses, and Rotaviruses (Estes and Ramig, 2001; Glass et al., 2006).

The name astrovirus was derived from the greek word astron and was used to describe small round viruses detected by electron microscopy in the stool of eight babies during an outbreak of diarrhoea and vomiting in infants in a maternity unit (Appleton, et al.,1977). These viruses are $27-34 \mathrm{~nm}$ in diameter, with the genome consisting of single -stranded RNA. The virus particle has smooth or slightly indented outer electron dense shell with an inner five or six star shaped core. Astroviruses have been found to be present in stool during mild gastroenteritis outbreak usually in children in infancy up to seven years of age (Blacklow and Greenberg, 1991). Symptoms of astrovirus infections are similar to those observed in rotavirus infections: fever, vomiting; diarrhoea and abdominal pains ( Lebaron et al., 1990). In the time past focus has been on bacterial, parasitic and rotavirus infections in our clinics leaving out other viruses that are equally responsible for diarrhoea, hence there is dearth of information on these other viruses. This work is aimed to determine the prevalence and the importance of astrovirus among children presenting with diarrhoea in Lagos State.

\section{Materials and Methods \\ Subjects and Sample Collection}

The study population comprised children whose ages were less than 5 years (under 60 months) old, who were hospitalised or admitted for acute diarrheal illness in Massey Children Hospital and the Pediatrics' section of Orile Agege General Hospital, between November 2007 and May 2008 in Lagos State, South Western part of Nigeria. Stool samples were collected into clean, labeled screw capped tubes (universal bottles) and stored frozen $\left(-20^{\circ} \mathrm{C}\right)$ at the Department of Microbiology, University of Lagos, Nigeria. Stools from non-diarrheic children of the same age bracket were also included in the collection as control. Children who happened to pass diarrhoeal stool during the visiting time to the health facility were enrolled in the study. Children with bloody stool or those who had other diseases in addition to diarrhoea were excluded. Diarrhoea is defined as the passage of 3 or more watery stool in the past 24hours before hospital visit. The consent of each parent or guardian was sought and obtained before enrolling his/her child (or children) in the study. Basic demographic and clinical information about the patients 
were obtained by administering questionnaires to the mothers or care givers. The hospitals were visited three times per week for sample collection and the study was not in any way interfering with the management of the patients. Only one stool specimen was collected per child. In all, a total of two hundred and fifteen $(n=215)$ faecal specimens (161 diarrhoea and 54 non diarrhoea ) were collected from eligible children into sterile open wide - mouthed containers and transported on ice packs to the laboratory where they were stored at $-20^{\circ} \mathrm{C}$ until analysed.

\section{Preparation of $10 \%$ faecal extract}

A $10 \%$ faecal extract / suspension was prepared by adding $0.1 \mathrm{~g}$ of solid or $200-500 \mu 1$ of each faeces depending on the consistency to $1 \mathrm{ml}$ of Phosphate buffered saline (PBS) / sample diluents in Eppendorf tube. The mixture was vortex for 30seconds and then centrifuge at 5000rpm (using KUBOTA 1120 bench-top centrifuge, Kubota Japan Corporation) for 3minutes at room temperature. The recovered supernatant (10\% faecal extract) was used for subsequent analyses.

\section{Astrovirus antigen detection}

The 215 stool samples were screened for human astroviruses using commercially available genus-specific kits (Astrovirus RIDASCREEN ${ }^{\circledR}$ r-Biopharm, Germany). The test was run according to the manufacturer's instructions. Approximately $100 \mu \mathrm{l}$ of each diluted specimen (supernatant) was dispensed into each micro well of a 96-well micro titre plate pre-coated with mouse monoclonal antibody $(\mathrm{MAb})$ against group specific antigen of astroviruses. Sample diluent $(100 \mu 1)$ was dispensed into the first and second wells as negative control and the kit-supplied inactivated astrovirus strain into third well as positive control. This was followed by adding $100 \mu 1$ of conjugate 1 to each micro well and incubated for 1 hour at room temperature. The plate was washed five times with diluted wash buffer (v/v 1:10), after which $100 \mu 1$ of conjugate 2 was added to each well and incubated for 30 minutes at room temperature. A second round of five washes with the diluted wash buffer was carried out after which $100 \mu 1$ of substrate was added into each micro well, followed by incubation at room temperature for 15 minutes in the dark. Reactivity was determined by spectrophotometry at $450 \mathrm{~nm}$ after adding $50 \mu 1$ of stop solution $(1 \mathrm{~N}$ sulfuric acid). The cut off value was calculated as the sum of the extinction for the negative control and 0.15 . The test results were interpreted according to the manufacturer's instruction.

\section{Data analysis}

Data obtained in the study was analyzed using the Prism version 5 (Graphpad software, San Diego, CA, USA). Infection proportions were tested for statistical significance by the use of Chi square. Differences were considered significant if $P$ $\leq 0.05$.

\section{Results}

Out of the 161 diarrheic stool samples screened for astrovirus 65 (40.4\%) were positive for human astrovirus while 6 $(11.1 \%)$ of the controls were also positive (Plate 1). Comparison of astrovirus positivity among the diarrheic and non-diarrheic (control) showed highly significant difference $\left(\mathrm{P}=0.005 ; \chi^{2}=15.654\right)$ in astrovirus infection among the diarrheic compared to the non-diarrheic group. Though males were found to be infected more than females in both the diarrhoeal and control cohorts; however there was no significant difference $\left(\mathrm{P}=0.101, \chi^{2}=2.691\right)$ in astrovirus positivity for the diarrheic; small sample size rendered the analysis for non-diarrheic group invalid (Table 1). A greater proportion of the positive cases occurred in children between 0 and 12 months of age. Proportions of infection among age groups was statistically significant $\left(\mathrm{P}=0.047 ; \chi^{2}=9.639\right)$; with age group $7-12$ months recording the highest prevalence (Table 2).

Table 1: Sex distribution of Astrovirus positivity among children in Lagos

\begin{tabular}{lllllll}
\hline & \multicolumn{3}{l}{ Diarrhoeic cohort } & \multicolumn{5}{l}{ Control cohort } \\
\cline { 2 - 7 } Sex & $\mathbf{N}$ & Positive & $\mathbf{\%}$ & $\mathbf{N}$ & Positive & \% \\
\hline Female & 70 & 28 & 40.0 & 26 & 1 & 3.9 \\
Male & 91 & 37 & 40.7 & 28 & 5 & 17.9 \\
Total & 161 & 65 & 40.4 & 54 & 6 & 11.1 \\
\hline
\end{tabular}

$\mathbf{N}=$ number tested 


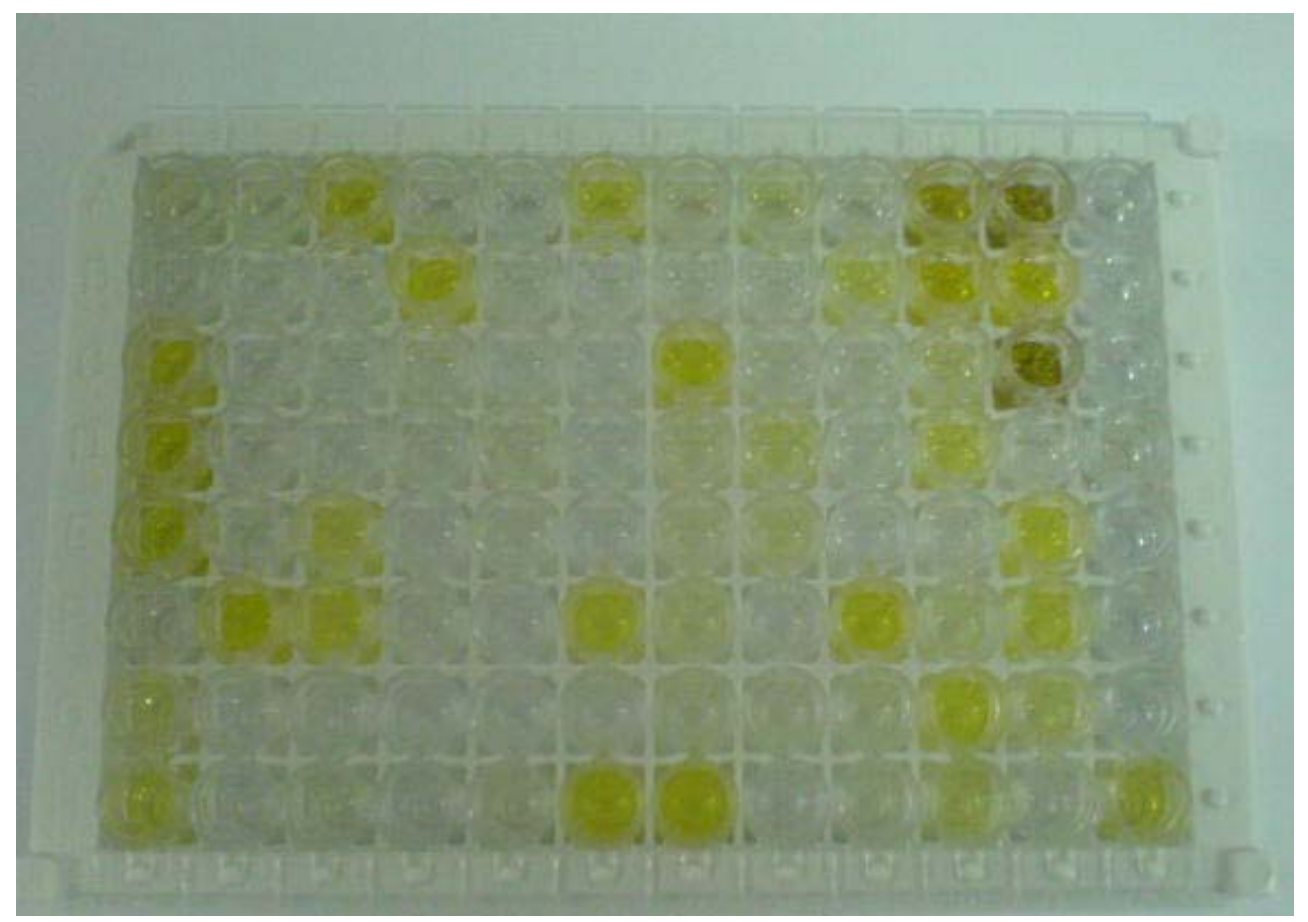

Plate 1: Microtitre plate showing ELISA result for Astrovirus detection.

Positive wells (yellow) and Negative wells (colourless).

Table 2: Age distribution of Astrovirus positivity among under 5years old children in Lagos.

\begin{tabular}{lcccccc}
\hline \multirow{2}{*}{$\begin{array}{l}\text { Age } \\
\text { (mth) }\end{array}$} & \multicolumn{2}{l}{ Diarrhoeic cohort } & \multicolumn{5}{c}{ Control cohort } \\
\cline { 2 - 6 } & $\mathbf{N}$ & Positive & $\mathbf{\%}$ & $\mathbf{N}$ & Positive & \% \\
\hline $0-6$ & 52 & 24 & 46.2 & 16 & 2 & 12.5 \\
& & & & & & \\
$7-12$ & 50 & 26 & 52.0 & 11 & 2 & 18.2 \\
$13-18$ & 22 & 6 & 27.3 & 8 & 0 & 10.0 \\
$19-24$ & 17 & 3 & 17.6 & 10 & 1 & 11.1 \\
$25+$ & 20 & 6 & 30.0 & 9 & 1 & $\mathbf{1 1 . 1}$ \\
Total & $\mathbf{1 6 1}$ & $\mathbf{6 5}$ & $\mathbf{4 0 . 4}$ & $\mathbf{5 4}$ & $\mathbf{6}$ & \\
\hline
\end{tabular}

\section{Discussion}

In this study, human astrovirus antigen was detected in 40.4 per cent $(65 / 161)$ of the stools from infants and young children with acute gastroenteritis presenting at hospitals in Lagos, Nigeria. This value is high and it falls within the range of astrovirus infection seen in children hospitalised with gastroenteritis in Brazil and India (Resque et al., 2007 and Gabbay et al., 2006) where prevalence of $29 \%$ and $55 \%$ were reported respectively. However, the prevalence observed in this study is higher than the $6.5 \%$ previously reported in Zaria, the northern part of Nigeria (Pennap et al., 2002). The reason for this could be due to regional differences, such as climate or other environmental and social factors. It was also observed that the children in the control group also excreted astrovirus at a relatively high level. This result confirms the studies of (Unicomb et al., 1998; Gaggero et al., 1998) who reported astrovirus as an agent implicated in mild or sub-clinical and even nosocomial infection.

Infection seems to be more in males than females but the difference was not significant however there was a high level of astrovirus shedding among the age groups, confirming the findings of (Steele et al., 1998; Palombo et al., 1996; Medina et al., 2000) who reported significant shedding of astrovirus in children between ages of 6 and 12 months. The age distribution of children revealed a significant difference in shedding of astrovirus with predominance among children less than 12 months old. The reason for this might not be unconnected with their immature immune system at this stage and might also be coupled with the fact that this is the age group when children crawl about picking all sorts of things into the mouth. 
The prevalence observed for astrovirus infection in this study among diarrhea children is of importance and calls for attention as it is very high, even when compared to the prevalence reported in Nigeria on the popular diarrhoeal agent - rotavirus (Paul and Erinle 1982; Avery et al., 1992; Ogunsanya et al., 1994 ;Aminu et al., 2008; Ayolabi et al., 2009), which happens to be the main focus of World Health Organisation among viral agents of diarrhea in children under 5years old (WHO, 2011).

This preliminary investigation has shown that astrovirus is an important agent found in the stool specimens of young children with diarrhoea in Lagos, Nigeria. The study also supports data from developing countries that astroviruses are commonly excreted in feaces of young children (Pennap et al., 2002; Steele et al., 1998). There is therefore the need to further investigate the role of astrovirus in the aetiology of acute infantile gastroenteritis and indicates the importance of including astrovirus detection assay in the routine testing of stools from young children with diarrhoea.

\section{References}

1. Aminu M., Esona M.D., Geyer A., Steele A.D. (2008). Epidemiology of rotavirus and astrovirus infections in children in North-western Nigeria. Annals of Afr. Med. 7 (4): 168-174.

2. Appleton H., Buckley M., Thom B. T., Cotton J. L and Henderson S. (1977). Virus-like particles in winter vomiting disease. Lancet 1: 409-411.

3. Avery, N. R.; Shelton, P. A.; Beards, M. G.; Omotunde, O. O.; Oyejide, C. O. and Olaleye, O. D. 1992. Viral agents associated with infantile gastroenteritis in Nigeria: relative prevalence of adenovirus serotypes 40 and 41 , astrovirus and rotavirus serotype 1 to 4. J. Diarrhoeal Dis. Resp. 10 (2)105-108

4. Ayolabi C. I. Akpan, I., Ojo, D. A., Armah, G. E and Emelogwu, R. (2009). Prevalence of rotavirus among children with diarrhoea in Lagos, Nigeria. Proc. $4^{\text {th }}$ UNILAG Conference and fair 63-70pp

5. Blacklow N. R. and Greenberg H. B. 1991. Viral gastroenteritis. New Engl. J. Med. 352: 252-263.

6. $\quad$ Christensen M. L. (1989). Human viral gastroenteritis. Clin. Microbial. 2 : 51-89.

7. Estes M. K. and Ramig F. (2001). Coding assignments and virion locations of rotavirus proteins and 3D structure of the rotavirus particle. $\mathrm{http} / /$ www.iah.bbsrc.ac.uk/dsRNAvirusproteins/rotavirus\%20figure.htm

8. Flewett T. H., Davies H., Braden A. S. and Robertson M. J. (1974). Diagnostic electron microscopy of faeces. Acute gastroenteritis associated with reovirus-like particles. J. Clin. Path. 27: 603-614.

9. Gabbay Y.B., Chamone C.B., Nakamura L.S., Oliveira D.S., Abreu S.F., Cavalcante-Pepino E.L., Mascarenhas J.D., Leite J.P. and Linhaes A.C. (2006). Characterisation of an astrovirus genotype 2 strain causing an extensive outbreak of gastroenteritis among Maxakali Indians, South-East Brazil. J. Clin. Virol. 37(4): 287-292.

10. Gaggero A., O'Ryan M., Noel J.S., Glass R.I., Monroe S.S., Mamani N., Prado V. and Avendano L.F. (1998). Prevalence of astrovirus infection among Chilean children with acute gastroenteritis. J. Clin. Microbiol. 36(12): 3691-3693.

11. Glass R.I., Bresee J., Jiang B., Parashar U., Yee E. and Gentsch J. 2006. Rotavirus and rotavirus vaccines. Adv. Exp. Med. Biol. 582: $45-54$.

12. Goodgame R. W. (2001). Viral causes of diarrhoea. Gastroenterol. Clin. North. Am. 30: 779-795.

13. Kakizawa J., Ushijima H., Wen L., Oseto M. (1997). Genetic analysis of the capsid region of human astrovirus serotype 3 isolated in Japan. Microbial. Immunol. $41: 637-640$.

14. Lebaron C.W., Lew J., Glass R.I., Weber J.M. and Ruiz-Palacios (Rotavirus study group) (1990). Annual rotavirus epidemic patterns in North America : results of a five years retrospective survey of 88 centers in Canada, Mexico and the United States. J. Am. Med. Assoc. 264: 983-988.

15. Medina S.M., Gutierrez M.F., Liprand F. and Ludert J.E. (2000). Identification and type distribution of astrovirus among children with gastroenteritis in Colombia and Venezuela. J. Clin. Microbiol. 38(9): 3481-3483.

16. Mims C., Playfair J., Roilt I., Wakelin D. and Williams R. (1999). Gastrointestinal tract infections. Medical Microbiology. $2^{\text {nd }}$ edition, Mosby London: 253-284pp.

17. Ogunsanya, T.I .; Rotimi . V. O. and Adenuga , A. 1994 . A study of the aetiological agents of childhood diarrhoea in Lagos, Nigeria. J. Med. Microbiol. 40: 10-14.

18. O’ Ryan M. (2005). New rotavirus vaccines: a reality at last. Rev. Chilena. Infectol. 22(4): 345-354.

19. Palombo E. A., Bugg H. C., Masendycz P. J., Coulson B. S., Barnes G. L. and Bishop R. F. 1996. Multiple-gene rotavirus reassortants responsible for an outbreak of gastroenteritis in Central and Northern Australia. J. Gen. Virol. 77(pt6): 1223-1227.

20. Paul, M .O. and Erinle, E .A. 1982. Influence of humility on rotavirus prevalence among Nigerian Infants and young children with gastroenteritis. J. Clin. Microbiol . 15(2): 212-215.

21. Pennap G., Pager C. T., Peenze I., de Beer M. C., Kwanga J. K. P., ogalla W. N., Umoh J. U. and Steele A. D. (2002). Epidemiology of astrovirus infection in Zaria, Nigeria. J. Tropical Paediatrics 48: $98-101$.

22. Resque H.R., Munford V., Castilho J.G., Schmich H., Caruzo T.A. and Racz M.L. (2007). Molecular characterization of astrovirus in stool samples from children in Sao Paulo, Brazil. Mem. Inst. Oswaldo Cruz 102 (8): 969-974.

23. Steele A.D., Basetse H.R., Blacklow N.R.,Herrmann J.E.(1998). Astrovirus infection in South Africa. A pilot study. Ann. Trop. Paediatr. 18: 315- 319.

24. Tiemessen C.T., Wegerhof F.O., Erasmus M.J. and Kidd A.H. 1989. Infection by enteric adenoviruses, rotaviruses and other agents in a rural African environment. J. Med. Virol. $28: 176$ - 182.

25. Unicomb,L.E, Banu,N. N, Azim, T. et al.(1998). Astrovirus infection in association with acute, persistent and nosocomial diarrhea in Bangladesh. Paediatr. Infect. Dis.J. 17 : 611 - 614.

26. World Health Organisation (2011). Rotavirus surveillance worldwide: In Weekly Epidemiological record 86 (18): 174-176. 